\title{
Effect of malaxation temperature on the physicochemical and sensory quality of $c v$. Cobrançosa olive oil and its evaluation using an electronic tongue
}

\author{
Ítala M.G. Marx ${ }^{\mathrm{a}, \mathrm{b}}$, Nuno Rodrigues ${ }^{\mathrm{a}}$, Ana C.A. Veloso ${ }^{\mathrm{c}, \mathrm{d}}$, Susana Casal ${ }^{\mathrm{b}}$, José A. Pereira ${ }^{\mathrm{a}}$, \\ António M. Peres ${ }^{\text {a, }}$ \\ ${ }^{a}$ Centro de Investigação de Montanha (CIMO), ESA, Instituto Politécnico de Bragança, Campus Santa Apolónia, 5300-253, Bragança, Portugal \\ ${ }^{\mathrm{b}}$ LAQV/REQUIMTE, Laboratory of Bromatology and Hydrology, Faculty of Pharmacy, University of Porto, Rua de Jorge Viterbo Ferreira, 228, 4050-313, Porto, \\ Portugal \\ ${ }^{\mathrm{c}}$ Instituto Politécnico de Coimbra, ISEC, DEQB, Rua Pedro Nunes, Quinta da Nora, 3030-199, Coimbra, Portugal \\ ${ }^{\mathrm{d}}$ CEB - Centre of Biological Engineering, University of Minho, Campus de Gualtar, 4710-057, Braga, Portugal
}

\section{A R T I C L E I N F O}

\section{Keywords:}

Malaxation

Olive oil quality

Health claim

Electronic tongue

Chemometrics

\begin{abstract}
A B S T R A C T
Olive oil is consumed worldwide due to its appreciated sensory attributes and health benefits, which are related with its fatty acid profile and richness in phenolic compounds that support a health claim concerning olive oil protective effects on blood lipids. However, to ensure that oils possess a rich phenolic content, the extraction conditions can be optimised. Therefore, the effects of malaxation temperature $\left(22,28\right.$ and $\left.34{ }^{\circ} \mathrm{C}\right)$ on the physicochemical and sensory characteristics of $c v$. Cobrançosa olive oils were evaluated. The oils extracted at $22{ }^{\circ} \mathrm{C}$ had an overall better physicochemical quality (higher total phenols content, greater oxidative stability, lower free acidity and oxidation markers) and more intense positive sensory sensations (higher bitterness and pungency). Additionally, this study showed that a potentiometric electronic tongue could be used to discriminate oils taking into account the effect of malaxation temperature on the overall physicochemical and sensory scores (all samples correctly classified for leave-one-out cross-validation) with a predictive classification similar to that achieved by trained panellists. This finding strengthens the hypothesis that this device could be used as a complementary/alternative taste tool for assessing the impact of the extraction conditions on the oils' physicochemical and sensory characteristics.
\end{abstract}

\section{Introduction}

Olive oil is the major external fat used in the Mediterranean diet and its consumption is related to well-known beneficial health effects (Marković, Torić, Barbarić, \& Brala, 2019). These effects are largely related to the oils' fatty acid profile and richness in phenolic compounds (Covas et al., 2006), namely in hydroxytyrosol and tyrosol molecular forms, which are the most representative phenolics of olive fruits and olive oil, particularly as esters of the secoiridoid elenolic acid (Napolitano, De Lucia, Panzella, \& D'Ischia, 2010). Furthermore, depending on the amounts of hydroxytyrosol and their derivates, some olive oils may be labelled with a health claim on the oxidative protection of blood lipids (Commission Regulation (EC) No. 432/2012, 2012). This possibility opened a commercial opportunity for olive oil producers that aim to produce new and differentiated oils that are in-line with the increasing worldwide consumers' demand for healthy foods (Pereira, Costa Freitas, Cabrita, \& Garcia, 2020). Besides, high total phenolic contents are related to higher oxidative stability and increased shelf-life (Servili \& Montedoro, 2002), being also responsible for the appreciated positive sensory attributes of olive oils (Peyrot Des Gachons et al., 2011). One strategy to ensure oils' natural enrichment in phenolic compounds is based on the optimization of the extraction operation conditions, namely using different malaxation/extraction time-temperature combinations (Angerosa, Mostallino, Basti, \& Vito, 2001; Gómez-Rico, Inarejos-García, Salvador, \& Fregapane, 2009; Guerrini et al., 2019; Jiménez, Sánchez-Ortiz, \& Rivas, 2014; Lukić et al., 2017; Taticchi et al., 2013; Trapani et al., 2017) or controlling/removing oxygen during malaxation (Miho, Moral, López-González, Díez, \& Priego-Capote, 2020;

\footnotetext{
* Corresponding author.

E-mail address: peres@ipb.pt (A.M. Peres).
} 
Servili et al., 2008), which have been studied for different monovarietal oils (e.g., cvs. Arbequina, Coratina, Cornicabra, Frantoio, Oglirola and Picual, among others). In general, according to the abovementioned literature, a higher malaxation time promotes a decrease of the olive oils' phenolic compounds. Regarding the malaxation temperature (MT) effect on the phenolic composition of the extracted oils opposite findings have been reported, being the conclusions reached dependent on the olive cultivar, the extraction plant scale (pilot or industrial plant), the olives' maturation index and the agro-climatic conditions. Similarly, the MT effects on the physicochemical and sensory profiles of olive oils are also not consensual and depend, apparently, on the olive cultivar, specific malaxation conditions and the plant scale used for the oils' extraction.

On other hand, physicochemical and sensory analysis of olive oils are, in most cases, time-consuming and expensive tasks. Physicochemical analysis requires several conventional analytical techniques (e.g., titration, spectrophotometry, high performance liquid chromatography and gas chromatography) while sensory assessment relies on the availability of trained sensory panels (Rodrigues, Casal, Peres, Baptista, \& Pereira, 2020). Regarding the sensory analysis, besides the scarcity of panellists, the low number of samples that can be assessed per day, together with the intrinsic complexity/difficulty in recognizing some attributes, emerges as important limitations of this procedure (Lanza \& Amoruso, 2020). Thus, potentiometric and voltammetric electronic tongues (E-tongues) have emerged has fast, accurate, cost-effective and user-friendly sensor-based tools for olive oil physicochemical and sensory analysis, namely for the classification of olive oils according to its quality grades, geographical origin or olive cultivar, olive oil adulteration, olive oil sensory evaluation, olive oil shelf-life estimation and quality evolution during storage (Apetrei, Ghasemi-Varnamkhasti, \& Apetrei, 2016; Borges, Peres, Dias, Seiquer, \& Pereira, 2018; Harzalli et al., 2018; Rodrigues et al., 2019; Veloso, Dias, Rodrigues, Pereira, \& Peres, 2016). Indeed, E-tongues with lipid polymeric sensor membranes possess global cross-sensitivity but low selectivity, and so, are not specific to any particular substance, similarly to the biological receptors of the human gustatory system (Wu, Tahara, Yatabe, \& Toko, 2020). The E-tongue sensing characteristics, which are related to the surface potential and charge density of the membranes, may be controlled by selecting the type and concentrations of the lipid additives and plasticizers of each lipid sensor membrane. The membrane's sensitivity is mainly affected by the concentration of the charged lipids inside the membrane being, for example, the sensitivity towards charged taste substances enhanced when low-density lipids are used. On the other hand, the selectivity of the membrane may be controlled by changing the hydrophobicity of its surface, which depends on the relative composition and type of lipids and plasticizers used. Higher lipid concentration leads to a more hydrophilic surface and, contrary, higher plasticizer concentration corresponds to a more hydrophobic surface (Wu, Tahara, et al., 2020). The capacity and versatility of E-tongues containing lipid sensors to qualitatively or quantitatively assess physicochemical compounds that can be related to different sensory gustatory sensations has been reported in the literature (Arca, Peres, Machado, Bona, \& Dias, 2019; Jeong et al., 2020; Oohira \& Toko, 1996; Oohira, Toko, Akiyama, Yoshihara, \& Yamafuji, 1995; Sharma et al., 2015; Slim et al., 2017; Toko, Hara, Tahara, Yasuura, \& Ikezaki, 2014; Veloso et al., 2016; Wu, Miyake, et al., 2020; Yasuura, Shen, Tahara, Yatabe, \& Toko, 2015) and recently reviewed by Wu, Tahara, Yatabe, and Toko (2020). In fact, polar compounds (acids, alcohols, aldehydes, esters and phenolic compounds, among others) can be naturally found in olive oils or in other olive products. These compounds have been related to different sensory positive attributes (e.g., acid, almonds, apple, banana, bitter, fruity, grassy, green, pungent, sweet sensations) and negative attributes (butyric, fusty, putrid, rancid, zapateria, wine-vinegary, wet-wood defects). The different chemical groups (e.g., hydroxyl, carboxyl, among other chemical groups) of the taste-related chemical compounds allow establishing electrostatic interactions or hydrogen bounds between them and the polar and non-polar regions of the lipid membranes, which present negative and positive polarities (Marx et al., 2018).

In this context, this study aimed to evaluate, for the first time, the effect of MT at an industrial level on the physicochemical and sensory attributes of $c v$. Cobrançosa olive oils (one of the most cultivated Portuguese olive cultivar). In fact, to the authors' best knowledge, no study has been devoted to study the effect of the MT on the physicochemical and sensory profile of $c v$. Cobrançosa oils industrially extracted, which is of utmost relevance since laboratory/pilot scale data are not always useful to predict effects on oils obtained with an industrial olive mill (Di Giovacchino, Sestili, \& Di Vincenzo, 2002). It was also intended to assess the feasibility of applying a potentiometric E-tongue as a physicochemical-taste device for discriminating the oils according to the MT by comparing its predictive classification performance with that achieved based on the sensory panel data. This last purpose comprises a key novelty of the study, i.e., the evaluation of the versatility of a potentiometric E-tongue to recognize oils extracted at different MT, which capability could be indirectly correlated with the MT effect on the overall physicochemical and sensory characteristics of the $c v$. Cobrançosa oils industrially extracted.

\section{Materials and methods}

\subsection{Olive oil samples}

Olives from the $c v$. Cobrançosa were harvested in mid-November 2018 from olive orchards located in Trás-os-Montes region (northeast Portugal). Oils were extracted in an industrial olive oil mill (OLIMONTES, Macedo de Cavaleiros, Portugal), at different MT (22, 28 and $34{ }^{\circ} \mathrm{C}$ ) during $60 \mathrm{~min}$ at 12 revolutions per min (RPM). These temperatures were chosen taking into account the malaxation temperature range (from 20 up to $45^{\circ} \mathrm{C}$ ) usually reported in the literature (Boselli, Di Lecce, Strabbioli, Pieralisi, \& Frega, 2009; Guerrini et al., 2019; Inajeros-García, Gómez-Rico, Salvador, \& Fregapane, 2009; Kalua et al., 2007; Ranalli, Contento, Schiavone, \& Simone, 2001; Stefanoudaki, Koutsaftakis, \& Harwood, 2011; Veneziani et al., 2017). A modern two-phase unit mill was used, being all the equipment in the extraction processing line from Alfa Laval (Italy). The line includes a hammer crusher, with a capacity of $5000 \mathrm{~kg}$ of olives per h and a sieve with 11 $\mathrm{mm}$ of diameter coupled with two malaxers (Type Gramula 700), each one with 4 bodies with capacity for $650 \mathrm{~kg}$ of paste, a two-phase horizontal decanter centrifuge, with a capacity of $5000 \mathrm{~kg}$ of paste per h, and a vertical centrifuge to remove wash/clean the olive oil (UVPX 507 AGT14). For each MT, six independent oil bottles were filled and then closed at the end of the processing line. The samples collected at the industrial olive oil mill were immediately sent to the laboratory (Bragança, Portugal). At the laboratory, the water traces in the oils were removed using anhydrous sodium sulfate $(5 \mathrm{~g}$ for $500 \mathrm{~mL}$ of olive oil), filtered through a cellulose filter (Peres, Martins, Mourato, Vitorino, \& Ferreira-Dias, 2016) and, stored in dark in amber glass bottles $(\sim 500$ $\mathrm{mL}$ ), totalizing 18 independent oils ( 3 temperatures $\times 6$ independent oils). All the analyses were performed 5 months after extraction to allow the full development of the olfactory and gustatory positive attributes of the olive oils (Rodrigues, Dias, Veloso, Pereira, \& Peres, 2017).

\subsection{Olive oil physicochemical and sensory analysis}

Four physicochemical quality parameters were evaluated, namely free acidity (FA, expressed as $\mathrm{g}$ of oleic acid per $100 \mathrm{~g}$ ), peroxide value ( $\mathrm{PV}$, in $\mathrm{mEq} \mathrm{O}_{2} / \mathrm{kg}$ ) and the two specific coefficients of extinction, at $232 \mathrm{~nm}$ and $268 \mathrm{~nm}\left(K_{232}\right.$, and $\left.K_{268}\right)$, as described in the European Union Regulation (Annexes II and IX in Commission Regulation (EEC) $\mathrm{N}^{\circ}$ 2568/91 from 11th July and amendments).

Also, the oxidative stability (OS, in h) of the oils was determined under accelerated oxidation conditions at $120^{\circ} \mathrm{C}$, using a Rancimat 743 apparatus (Metrohm $\mathrm{CH}$, Switzerland) as described by Rodrigues et al. 
(2019). Total phenolic contents (TPC) were also determined according to Capannesi, Palchetti, Mascini, and Parenti (2000) with some modifications. Approximately $5 \mathrm{~g}$ of olive oil were mixed with $5 \mathrm{~mL}$ of $n$-hexane and further agitated in a vortex during $30 \mathrm{~s}$. After, $25 \mathrm{~mL}$ of an aqueous methanolic solution $\left(\mathrm{MeOH} / \mathrm{H}_{2} \mathrm{O} 80: 20 \mathrm{v} / \mathrm{v}\right)$ were added and the final solution was mixed (vortex) for 1-2 min and centrifuged at 6000 RPM for $10 \mathrm{~min}$. The nonpolar fraction (upper phase) was discarded and the polar extract was subjected to analysis. One milliliter of the extract was mixed with $1 \mathrm{~mL}$ of Folin-Ciocalteu reagent, $1 \mathrm{~mL}$ of $\mathrm{Na}_{2} \mathrm{CO}_{3}$ solution $(7.5 \mathrm{~g} / 100 \mathrm{~mL})$, and $7 \mathrm{~mL}$ of deionized water. After homogenization, the mixture was stored overnight and spectrophotometrically analyzed $(\lambda=765 \mathrm{~nm})$. For quantification purposes, a calibration curve between the measured absorbance and the concentration of gallic acid in methanol was established (dynamic concentration range: $0.01-0.5 \mathrm{mg} / \mathrm{mL} ; R^{2}$-Pearson $\geq 0.999$ ). The TPC were expressed as $\mathrm{mg}$ of gallic acid equivalents (GAE) per $\mathrm{kg}$ of oil. All samples were analyzed in duplicate, totalizing 36 assays ( 3 temperatures $\times 6$ independent oils $\times 2$ assays). This polar extract was also used for the E-tongue measurements, as detailed below.

The quality grade of the samples was set considering the physicochemical levels and sensory data, following the methodologies described by the European Union standard methods (Annexes II and IX in the Commission Regulation (EEC) No 2568/91 from 11th July and amendments). Each olive oil sample was also evaluated by 8 trained panellists of the olive oil sensory panel of the School of Agriculture of the Polytechnic Institute of Bragança, Portugal (Rodrigues et al., 2020). The intensity of the positive or negative attributes were scored according to an unstructured continuous intensity scale ranging from 0 (no sensory sensation perceived) to 10 (maximum intensity of the sensory sensation perceived), following the abovementioned European Regulation. The descriptive profile was assessed using a test sheet with some modification following the recommendations of the International Olive Council (IOC) (COI/T.20/Doc. no. November 22, 2005). The intensities of olfactory and gustatory attributes were assessed as described in a previous work by Rodrigues et al. (2020).

\subsection{E-tongue}

A lab-made potentiometric E-tongue multisensor device, comprising two cylindrical arrays was used (Rodrigues et al., 2019). Each array contained 20 lipid polymeric cross-sensitive sensor membranes (40 sensors in total) that contain different mixtures of additive compounds (methyltrioctylammonium chloride, octadecylamine, oleic acid and oleyl alcohol) and plasticizers (bis(1-butylpentyl) adipate, dibutyl sebacate, dioctyl phenylphosphonate, 2-nitrophenyl-octyl ether and tris (2-ethylhexyl) phosphate). The type lipid polymeric sensors and their compositions were selected based on the literature (Dias et al., 2009). This type of lipid membranes possesses suitable signal stability over time (relative standard deviations, RSD, lower than 0.05 for a $5 \mathrm{~h}$ time-period) for both standard solutions and real samples (Dias et al., 2009), being possible to be re-used during at least one-year time period without requiring any replacement of the sensor membranes. Also, the sensors showed satisfactory intra- and inter-day repeatabilities $(0.001 \leq$ RSD $\leq 0.15$ ) towards standard chemical solutions that mimicked the five basic taste sensations (sweet, acid, bitter, salty and umami) (Dias et al., 2009; Marx et al., 2017a; Veloso et al., 2018) or olive oils' alcoholic aqueous extracts (Veloso et al., 2018). Additionally, it has been found that these sensor membranes allowed establishing quantitative semi-logarithmic responses between the potentiometric signals and the concentration of different chemical compounds that mimic positive and negative sensory attributes usually perceived in olives or olive oils (Marx et al, 2017a, 2017b; Slim et al., 2017).

The E-tongue device was connected to an Agilent Data Acquisition unit (model 34970 A), which was controlled by an Agilent BenchLink Data Logger software. For the olive oil analysis, the polar extract obtained in section 2.2 was used. Briefly, $20 \mathrm{~mL}$ of extract was diluted to a final volume of $100 \mathrm{~mL}$ with deionized water and mixed for 1-2 min using a vortex. Then, the solutions were immediately analyzed with the E-tongue, for 5-min, which allowed reaching a pseudo-equilibrium between the E-tongue non-specific lipid polymeric membranes and the chemical compounds present in each diluted extract solution. In fact, after $5 \mathrm{~min}$ of analysis the potentiometric signal of each lipid polymeric membrane reached an almost constant potential value (data not shown), showing that the equilibrium was reached, allowing a fast analysis time. Electrochemical assays were performed in duplicate for each sample, with a third assay carried out if the potentiometric signal of any of the 40 sensors showed a RSD greater than 0.20 (value set according to the IOC regulations for sensory analysis) (Rodrigues et al., 2019). After each assay the E-tongue was washed with deionized water. The E-tongue was further stored at room temperature and immersed into a $\mathrm{HCl}$ cleaning solution $(0.01 \mathrm{~mol} / \mathrm{L})$, which ensured the lipid polymeric membranes integrity and functionality during long time-period (over one year).

\subsection{Statistical analysis}

The statistical significance of the MT on the physicochemical and sensory quality of the industrially extracted oils from cv. Cobrançosa olives was assessed using one-way ANOVA followed, when appropriate, by the Tukey's post-hoc multi-comparison test. Also, when a significant effect was found, the Pearson correlation coefficient ( $R$-Pearson) was determined to infer about the existence of a linear correlation between the olive oils' physicochemical and sensory characteristics and the MT.

Principal component analysis (PCA) was used as an unsupervised multivariate classification technique for assessing the overall influence of the malaxation temperature on the physicochemical and sensory profiles of the studied oils. The results were discussed based on the $2 \mathrm{D}$ plots of the first three principal component (PC) functions, taking into account the percentage of the variance explained.

Finally, linear discriminant analysis (LDA) was further applied to evaluate the correct classification of the oils according to the MT using either the sensory analysis data or the potentiometric E-tongue. The best subsets of sensory attributes or E-tongue sensors were identified using the meta-heuristic simulated annealing (SA) variable selection algorithm aiming inferring about the possible use of the E-tongue as a complementary/alternative sensory tool. So, mathematical discriminant models were established as linear combinations of the independent variables (i.e., sensory data or E-tongue sensor signals) aiming to achieve the best separation of the different supervised groups under study (i.e., the three different MT). The methodology involved two steps. Firstly, the most informative independent non-redundant variables (i.e., sensory sensations or sensors) were selected by using the SA algorithm (Bertsimas \& Tsitsiklis, 1993; Cadima, Cerdeira, \& Minhoto, 2004). This is a key step considering that sensory data and mostly the potentiometric signals recorded by the E-tongue, can show a high multicollinearity level. The SA algorithm selects the optimal conditions based on the assumptions of the annealing physic process using an iterative procedure. The algorithm searches for a global minimum that optimizes a system with $\mathrm{k}$ variables. In each iteration, the solutions of the current and the new subsets of $\mathrm{k}$ variables are compared using the tau2 quality criterion, which is a measure of the goodness of fitting. A new solution is randomly searched in the neighbourhood of the current solution, being selected if it gave a better result than the initial one. In general, 10,000 attempts are used to choose the best subset of variables (best model), starting the process of selecting the best subsets of variables on each trial, thus ensuring greater confidence in finding a truly optimal solution. In the present study, for each sub-set of independent variables under evaluation (sensory data or E-tongue sensors), the set of sensors chosen was the one that enabled the maximum value of tau2 (Cadima et al., 2004). Secondly, the classification performance of each selected LDA-SA model was evaluated using a leave-one-out (LOO) cross-validation (CV) procedure, which is an internal CV variant, usually applied to minimize the risk of overoptimistic correct classification results. This methodology 
enabled to evaluate the model's prediction performance by removing a set of $\mathrm{n}$ samples from the database and then predict their rank with the LDA-SA model established with the remaining $n-1$ samples. This process is repeated $n$ times, to obtain the classification errors of all the samples, being the overall sum of errors for each test divided by $n$. The LOO-CV technique has proven to be an adequate internal validation procedure when the number of samples is low.

All statistical analyses were performed using the Sub-select (Cadima et al., 2004) and MASS (Venables \& Ripley, 2002) packages of the open-source statistical program $\mathrm{R}$ (version 2.15.1), at a significance level of 0.05 .

\section{Results and discussion}

\subsection{Effect of malaxation temperature on the physicochemical and sensory characteristics of olive oils}

Malaxation plays a key role in the final quality and composition of olive oils (Clodoveo, 2012). Thus, $c v$. Cobrançosa olive oils were extracted at different MT $\left(22,28\right.$ and $\left.34{ }^{\circ} \mathrm{C}\right)$ to evaluate the effect on the physicochemical quality (FA, PV, $K_{232}, K_{268}, \mathrm{OS}, \mathrm{TPC}$ ) and sensory sensations (olfactory and gustatory attributes). The physicochemical and sensory data are shown in Tables 1 and 2, respectively. Based on the results, and independently of the MT studied, all obtained olive oils could be classified as EVOO (FA $\leq 0.8 \mathrm{~g}$ oleic acid/100 g, PV $\leq 20 \mathrm{mEq}$ $\mathrm{O}_{2} / \mathrm{kg}, K_{232} \leq 2.50, K_{268} \leq 0.22$; fruity intensity greater than 0 and intensity of defects equal to 0 ) (Commission Delegated Regulation (EU) $2015 / 1830$ of 8th July). In all samples evaluated, the fruity olfactory and gustatory sensation perceived was classified as "green". Regarding the physicochemical parameters evaluated it should be noticed that the FA, PV, $K_{232}, K_{268}$, OS and TPC values (Table 1 ) are lower than those reported in the literature for $c v$. Cobrançosa oils extracted at $28-30{ }^{\circ} \mathrm{C}$ (Peres et al., 2016). The observed differences could be tentatively attributed to the olives ripening stage and to the different production scales used (Abencor pilot plant versus industrial plant). Indeed, Inajeros-García et al. (2009) verified that $c v$. Cornicabra olive oils extracted at laboratory scale had higher OS and TPC than those produced at industrial scale using the same MT.

Regarding the MT effect (Table 1), it was verified that higher temperatures significantly increased the FA, PV and $K_{232}$ values (1.36, 2.74 and 1.13 times, respectively, from $22{ }^{\circ} \mathrm{C}$ to $34{ }^{\circ} \mathrm{C}$ ) and decreased the TPC

Table 1

Physicochemical parameters (mean \pm standard deviation) of $c v$. Cobrançosa olive oils industrially extracted at different malaxation temperatures $(22,28$ and $\left.34{ }^{\circ} \mathrm{C}\right)$.

\begin{tabular}{llllll}
\hline \multirow{2}{*}{$\begin{array}{l}\text { Physicochemical } \\
\text { parameters }\end{array}$} & \multicolumn{3}{l}{ Malaxation Temperature } & \multirow{2}{*}{$P$-value } & $\begin{array}{l}R \text { - } \\
\text { Pearson }\end{array}$ \\
\cline { 2 - 3 } & $22{ }^{\circ} \mathrm{C}$ & $28{ }^{\circ} \mathrm{C}$ & $34^{\circ} \mathrm{C}$ & & \\
\hline Free acidity (FA, g oleic & $0.11 \pm$ & $0.16 \pm$ & $0.15 \pm$ & $<0.0001$ & +0.769 \\
acid/100 g) & $0.00^{\mathrm{A}}$ & $0.01^{\mathrm{B}}$ & $0.01^{\mathrm{B}}$ & & \\
Peroxide value (PV, & $2.3 \pm$ & $3.7 \pm$ & $6.3 \pm$ & 0.0001 & +0.983 \\
mEq $\mathrm{O}_{2} / \mathrm{kg}$ olive oil) & $0.6^{\mathrm{A}}$ & $0.9^{\mathrm{A}}$ & $1.6^{\mathrm{B}}$ & & \\
$K_{232}$ & $1.75 \pm$ & $1.78 \pm$ & $1.99 \pm$ & $<0.0001$ & +0.905 \\
& $0.04^{\mathrm{A}}$ & $0.02^{\mathrm{A}}$ & $0.04^{\mathrm{B}}$ & & \\
$K_{268}$ & $0.18 \pm$ & $0.18 \pm$ & $0.18 \pm$ & 0.7282 & - \\
& 0.01 & 0.01 & 0.07 & & \\
Oxidative stability (OS, & $13.6 \pm$ & $13.1 \pm$ & $12.7 \pm$ & 0.1126 & - \\
h) & 0.5 & 0.3 & 0.8 & & \\
Total phenols content & $225 \pm$ & $205 \pm 5^{\mathrm{B}}$ & $190 \pm$ & $<0.0001$ & -0.997 \\
(TPC, mg GAE/kg & $15^{\mathrm{A}}$ & & $11^{\mathrm{C}}$ & & \\
olive oil) & & & & & \\
\hline
\end{tabular}

$P$-values for the one-way ANOVA.

$R$-Pearson coefficients: between each parameter and the malaxation temperatures.

Means $(n=12)$ in the same line with the same uppercase letter are not significantly different from a statistical point of view according to the Test of Tukey, at a significance level of 0.05 .
(0.84 times) ( $P$-value $<0.001$, for one-way ANOVA). Moreover, positive linear correlations with the temperature were found for both FA and PV, $(+0.905 \leq R$-Pearson $\leq+0.983)$, and a negative linear correlation was observed for TPC ( $R$-Pearson $=-0.997)$. This latter finding clearly pointed out the possibility of increasing the oils' phenolic content by decreasing the MT and so, to obtain oils with increased health benefits. Contrary, no significant effects were found for $K_{268}$ and OS ( $P$-value < 0.05 , for one-way ANOVA), although for the latter a slight decrease was observed for higher temperatures. Thus, a MT of $22{ }^{\circ} \mathrm{C}$ allowed extracting olive oils with overall superior physicochemical quality and, supposedly, with higher health beneficial effects due to the greater TPC.

The findings regarding FA, PV and the extinction coefficients are, in general, in agreement with the literature data for oils obtained from other olive cultivars. Indeed, Ranalli et al. (2001) reported that when MT rise from 30 to $35{ }^{\circ} \mathrm{C}$ a higher lipase activity was observed leading to an increase of the FA as well as to an intensification of primary (increasing $K_{232}$ and PV) and secondary oxidations (increasing $K_{270}$ values). Other studies also reported a considerable increase of the FA and PV with MT rise (Boselli et al., 2009; Parenti, Spugnoli, Masella, \& Calamai, 2008; Stefanoudaki et al., 2011).

Concerning the effect of MT on the OS and TPC, contradictory findings have been reported. Several studies described that both OS and TPC increased with MT (from 20 to $45^{\circ} \mathrm{C}$ ) (Boselli et al., 2009; Guerrini et al., 2019; Inajeros-García et a., 2009; Kalua et al., 2007; Ranalli et al., 2001; Stefanoudaki et al., 2011; Veneziani et al., 2017), tentatively explained by an increased release of phenols from the olives' cell wall or from other tissues (Taticchi et al., 2013), or due to the rise of the partition coefficient of the phenols between the oil and water phases (Gómez-Rico et al., 2009). Other works reported a decreasing trend of TPC with the temperature rise (Angerosa, Mostallino, Basti, \& Raffaella, 2001; Miho et al., 2020; Ranalli, Malfatti, Lucera, Contento, \& Sotiriou, 2005; Servili, Selvaggini, Taticchi, Esposto, \& Montedoro, 2003), as observed in this study. Indeed, higher temperatures promote the oxidative degradation of secoiridoids due to the enhanced activity of native oxidoreductases (Servili \& Montedoro, 2002) as well as the hydrolysis of oleuropein and demethlyoleuropein by $\beta$-glucosidase (Clodoveo, 2012).

As expected from the previous discussion, the MT influenced the physicochemical (FA, PV, $K_{232}, K_{268}$, OS and TPC) profiles of the studied olive oils, which can be inferred from the 2D-PCA plots (Fig. 1) of the three first principal components (PC1, PC2 and PC3 that explained 62.5, 15.4 and 10.6 percent of the physicochemical data variability). Indeed, the physicochemical data can be successfully used to unsupervisely split (PCA plots) the oils according to the MT, pointing out their thermaldependency as well as the greater impact of the higher temperature ( $34{ }^{\circ} \mathrm{C}$, for which $\mathrm{FA}, \mathrm{PV}, K_{232}$ and $K_{268}$ parameters had a greater contribution) compared to the lower temperatures $\left(22\right.$ and $28{ }^{\circ} \mathrm{C}$, for which OS and TPC had the most influence), with an observed slight data overlapping that may indicate an overall similar impact of these two lower temperatures.

In which concerns the sensory analysis, the trained panellists perceived 7 olfactory sensations (apple, cabbage, dry fruits, fresh herbs, green, tomato and tomato leaves) and 10 gustatory sensations (apple, bitter, cabbage, dry fruits, green, fresh herbs, pungent, sweet, tomato and tomato leaves) as listed in Table 2 . The reported mean intensities and respective standard deviations were calculated from the intensity values perceived by each of the 8 panellists during the evaluation (in duplicate) of the six independent oils collected for each MT. A mean and standard deviation equal to zero signifies that the attribute was not perceived by any member of the sensory panel in any of the independent sample/replica of the oils extracted at a specific MT (olfactory and gustatory cabbage sensation for 28 and/or $34{ }^{\circ} \mathrm{C}$ ). According to the evaluation performed by the panellists (Table 2 and Fig. 2), it is clear that, except for the sweet gustatory attribute, the intensities of the overall olfactory and gustatory positive sensations decreased with the increase of the MT ( $P$-value $<0.001$, for one-way ANOVA), being 
Table 2

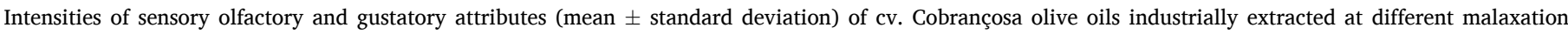
temperatures $\left(22,28\right.$ and $\left.34^{\circ} \mathrm{C}\right)$, assessed by 8 trained panellists.

\begin{tabular}{|c|c|c|c|c|c|c|}
\hline \multirow[t]{2}{*}{ Sensory attributes } & & \multicolumn{3}{|c|}{ Malaxation Temperature } & \multirow[t]{2}{*}{$P$-value } & \multirow[t]{2}{*}{$R$-Pearson } \\
\hline & & $22{ }^{\circ} \mathrm{C}$ & $28^{\circ} \mathrm{C}$ & $34^{\circ} \mathrm{C}$ & & \\
\hline \multirow[t]{8}{*}{ Olfactory sensations } & Green & $7.5 \pm 0.6^{\mathrm{A}}$ & $6.0 \pm 0.5^{\mathrm{B}}$ & $5.4 \pm 0.5^{\mathrm{C}}$ & $<0.0001$ & -0.975 \\
\hline & Apple & $6.0 \pm 0.5^{\mathrm{A}}$ & $3.3 \pm 0.6^{\mathrm{B}}$ & $3.0 \pm 0.6^{\mathrm{B}}$ & $<0.0001$ & -0.903 \\
\hline & Tomato & $5.2 \pm 1.3^{\mathrm{A}}$ & $4.7 \pm 0.6^{\mathrm{A}}$ & $4.2 \pm 0.7^{\mathrm{B}}$ & 0.0474 & -0.999 \\
\hline & Dry fruits & $2.6 \pm 1.0^{\mathrm{A}}$ & $3.3 \pm 1.1^{\mathrm{A}}$ & $1.8 \pm 0.3^{\mathrm{B}}$ & 0.0026 & -0.561 \\
\hline & Tomato leaves & $5.4 \pm 0.6^{\mathrm{A}}$ & $4.1 \pm 0.6^{\mathrm{B}}$ & $3.3 \pm 0.8^{\mathrm{C}}$ & $<0.0001$ & -0.990 \\
\hline & Fresh herbs & $3.7 \pm 1.5^{\mathrm{A}}$ & $2.8 \pm 0.9^{\mathrm{B}}$ & $2.5 \pm 0.4^{\mathrm{B}}$ & 0.0489 & -0.964 \\
\hline & Cabbage & $5.5 \pm 0.8^{\mathrm{A}}$ & $0.3 \pm 1.0^{\mathrm{B}}$ & $0.0 \pm 0.0^{\mathrm{B}}$ & $<0.0001$ & -0.889 \\
\hline & Harmony & $8.2 \pm 0.2^{\mathrm{A}}$ & $8.0 \pm 0.2^{\mathrm{A}}$ & $7.1 \pm 0.8^{\mathrm{B}}$ & $<0.0001$ & -0.943 \\
\hline \multirow[t]{11}{*}{ Gustatory sensations } & Green & $7.5 \pm 0.4^{\mathrm{A}}$ & $6.3 \pm 0.6^{\mathrm{B}}$ & $5.9 \pm 0.5^{\mathrm{B}}$ & $<0.0001$ & -0.967 \\
\hline & Sweet & $1.9 \pm 0.5^{\mathrm{A}}$ & $2.4 \pm 0.9^{\mathrm{A}}$ & $2.8 \pm 0.6^{\mathrm{B}}$ & 0.0189 & +0.999 \\
\hline & Bitter & $5.6 \pm 0.6^{\mathrm{A}}$ & $5.1 \pm 0.6^{\mathrm{A}}$ & $4.6 \pm 0.6^{\mathrm{B}}$ & 0.0011 & -0.999 \\
\hline & Pungent & $6.0 \pm 0.7$ & $5.4 \pm 1.0$ & $5.4 \pm 1.0$ & 0.2809 & - \\
\hline & Apple & $4.8 \pm 0.6^{\mathrm{A}}$ & $3.1 \pm 0.6^{\mathrm{B}}$ & $2.9 \pm 0.6^{\mathrm{B}}$ & $<0.0001$ & -0.907 \\
\hline & Tomato & $6.3 \pm 0.6^{\mathrm{A}}$ & $4.9 \pm 0.7^{\mathrm{B}}$ & $4.3 \pm 0.6^{\mathrm{B}}$ & $<0.0001$ & -0.977 \\
\hline & Dry fruits & $2.6 \pm 0.5^{\mathrm{B}}$ & $3.5 \pm 0.8^{\mathrm{A}}$ & $2.2 \pm 0.4^{\mathrm{B}}$ & $<0.0001$ & -0.305 \\
\hline & Fresh herbs & $3.4 \pm 1.4$ & $3.3 \pm 0.5$ & $2.5 \pm 0.3$ & 0.0651 & - \\
\hline & Cabbage & $4.5 \pm 0.7^{\mathrm{A}}$ & $0.0 \pm .0 .0^{\mathrm{B}}$ & $0.0 \pm 0.0^{\mathrm{B}}$ & $<0.0001$ & -0.866 \\
\hline & Tomato leaves & $5.5 \pm 0.8^{\mathrm{A}}$ & $4.5 \pm 0.7^{\mathrm{B}}$ & $3.5 \pm 0.8^{\mathrm{C}}$ & $<0.0001$ & -0.999 \\
\hline & Harmony & $7.5 \pm 0.5^{\mathrm{A}}$ & $7.4 \pm 0.3^{\mathrm{A}}$ & $6.7 \pm 0.3^{B}$ & 0.0001 & -0.949 \\
\hline \multirow[t]{2}{*}{ Global sensations } & Persistence & $8.7 \pm 0.3$ & $8.1 \pm 0.7$ & $8.3 \pm 0.7$ & 0.0668 & - \\
\hline & Complexity & $7.3 \pm 0.5^{\mathrm{A}}$ & $6.6 \pm 0.5^{\mathrm{B}}$ & $6.2 \pm 0.5^{\mathrm{B}}$ & $<0.0001$ & -0.987 \\
\hline
\end{tabular}

$P$-values for the one-way ANOVA.

$R$-Pearson coefficients: between each parameter and the malaxation temperatures.

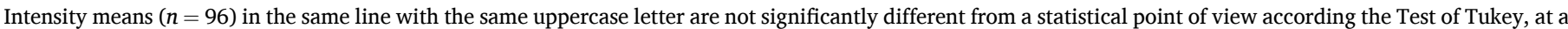

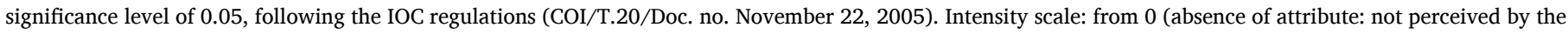
panellists) to 10 (maximum attribute intensity).
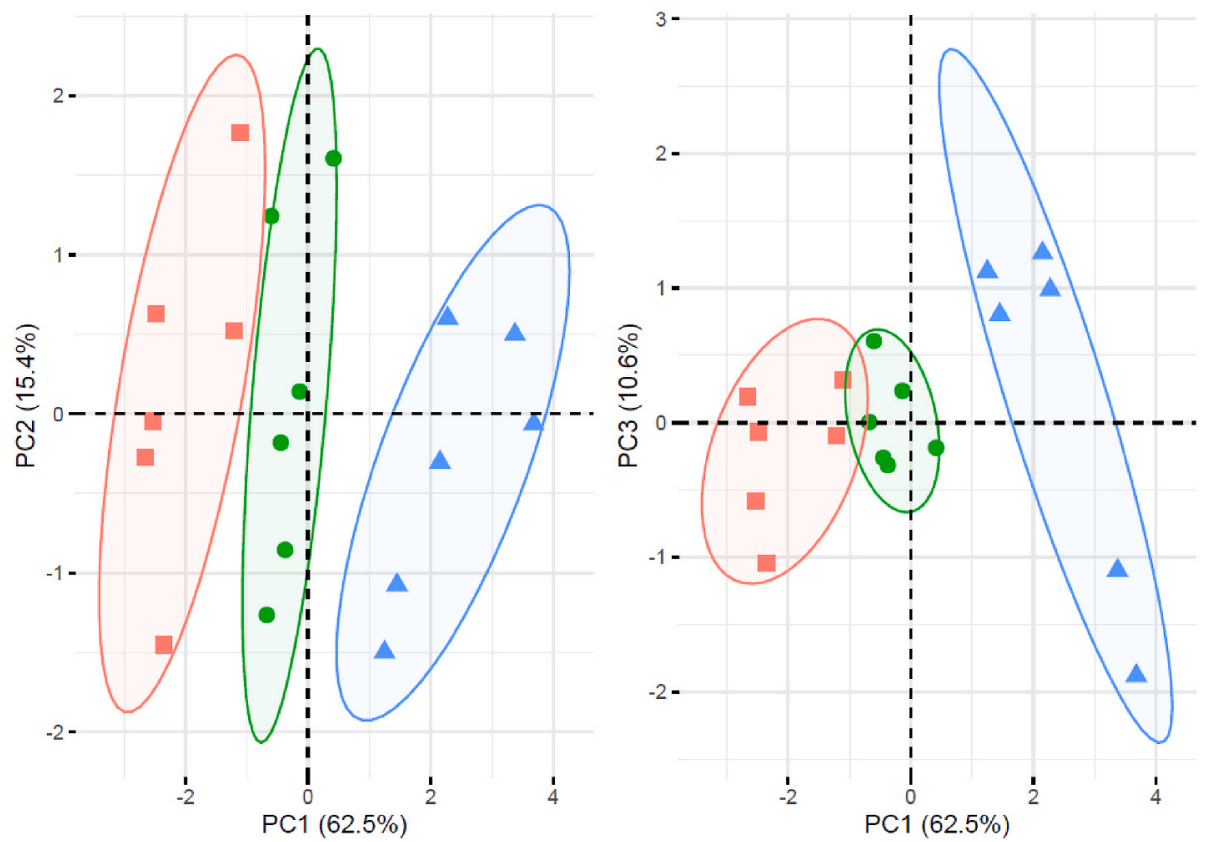

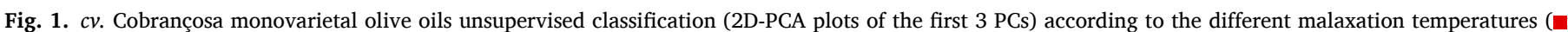

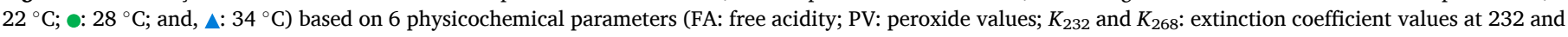
$268 \mathrm{~nm}$, respectively; and, TPC: total phenols contents).

possible to establish negative linear correlations between the attribute intensity and the temperature $(-0.999 \leq R$-Pearson $\leq-0.903)$.

The overall decreasing trends are in agreement with the findings of Stefanoudaki et al., 2011 that studied the intensities of pungent, bitter, artichoke, bitter almond, cut green and fruity sensations perceived in oils extracted at MT varying from 15 to $42{ }^{\circ} \mathrm{C}$. The decrease of the intensity with the MT was attributed to the direct decrease in the concentration of phenolic compounds and to the inactivation of enzymes (e.g., lipoxygenase and hydroperoxide lyase), which reduced the production of key sensory volatile compounds. Similarly, Boselli et al. (2009) reported that the bitterness of oils extracted in a continuous industrial plant slightly decreased with the MT (from 25 to $45^{\circ} \mathrm{C}$ ). However, Lukić et al. (2017) observed slightly higher intensities of fruit and tomato attributes for $c v$. Oblica oils when the MT rise from 22 to $30^{\circ} \mathrm{C}$, 
(A) Olfactory attributes

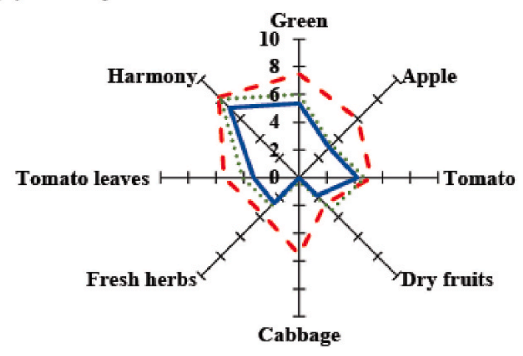

(B) Gustatory attributes

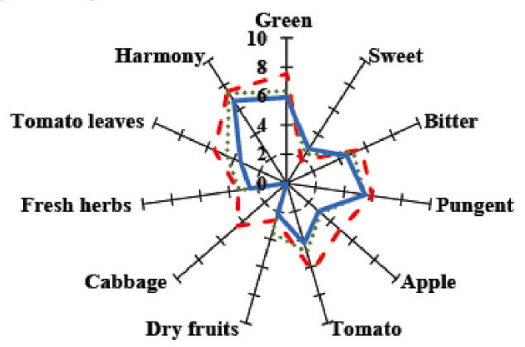

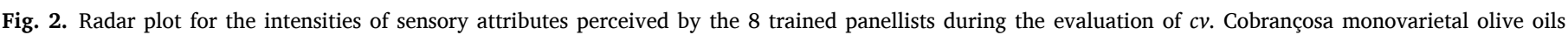

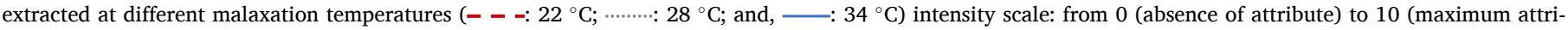
bute intensity).

while green grass/leaves and dry fruits olfactory sensations were more intense at the lowest temperature.

In summary, the olfactory attributes seem to be more prone to the MT than the gustatory attributes and the $c v$. Cobrançosa oils extracted at $22{ }^{\circ} \mathrm{C}$ had, in general, a better sensory quality, with higher intensities of the olfactory-gustatory sensations usually appreciated by the consumers. As can be seen from Fig. 3, the different sensory profiles (olfactory and gustatory attributes) established by the trained panellists allowed a clear unsupervised split (2D-PCA plots) of the oils according to the MT. The three first PCs allowed explaining 53.0, 14.7 and 8.5 percent of the sensory data variability, respectively. Contrary to the inference established from the physicochemical data, the olfactory and gustatory data pointed out that oils extracted at $22{ }^{\circ} \mathrm{C}$ were more different, from a sensory point of view (more pronounced green, apple, cabbage and bitter sensations), than those extracted at $28-34{ }^{\circ} \mathrm{C}$ (with closest groups). This successful unsupervised oils' grouping clearly shows the expected impact of the malaxation temperature on the sensory characteristics of the olive oils.

Finally, as expected, oils with a more intense bitterness possessed higher TPC $(R$-Pearson $=+0.998)$, being this trend in agreement with the literature data (Boselli et al., 2009). It should be remarked that the use of malaxation temperatures lower than $35{ }^{\circ} \mathrm{C}$ do not affect the oil extraction yield, being no significant yield losses reported in previous studies (Ranalli et al., 2001).

3.2. Discrimination of olive oils according to the sensorial attributes imposed by the malaxation temperature used during their extraction

Malaxation conditions, namely temperature, highly influence the physicochemical and sensory characteristics of the olive oils. For $c v$. Cobrançosa oils it was found that a lower MT $\left(22{ }^{\circ} \mathrm{C}\right)$ during the industrial extraction process would contribute to the production of olive oils with better physicochemical and sensory qualities. However, as known, the conventional analytical techniques used to assess these attributes are time-consuming and sometimes expensive, which is far away from the economic and technical capability of small producers. In this context, the development of sensor-based devices is of utmost relevance.

Therefore, a potentiometric E-tongue-LDA-SA model was developed aiming to classify olive oils according to the MT, i.e., to the temperature effect on the physicochemical and sensorial profiles of the oils (as discussed in the previous section). The predictive classification performance was compared to that achieved with the sensory-LDA-SA model.

The sensory-LDA-SA model used the data of 8 selected nonredundant olfactory-gustatory attributes (5 olfactory sensations: apple, cabbage, dry fruits, fresh herbs and tomato leaves; plus, 3 gustatory
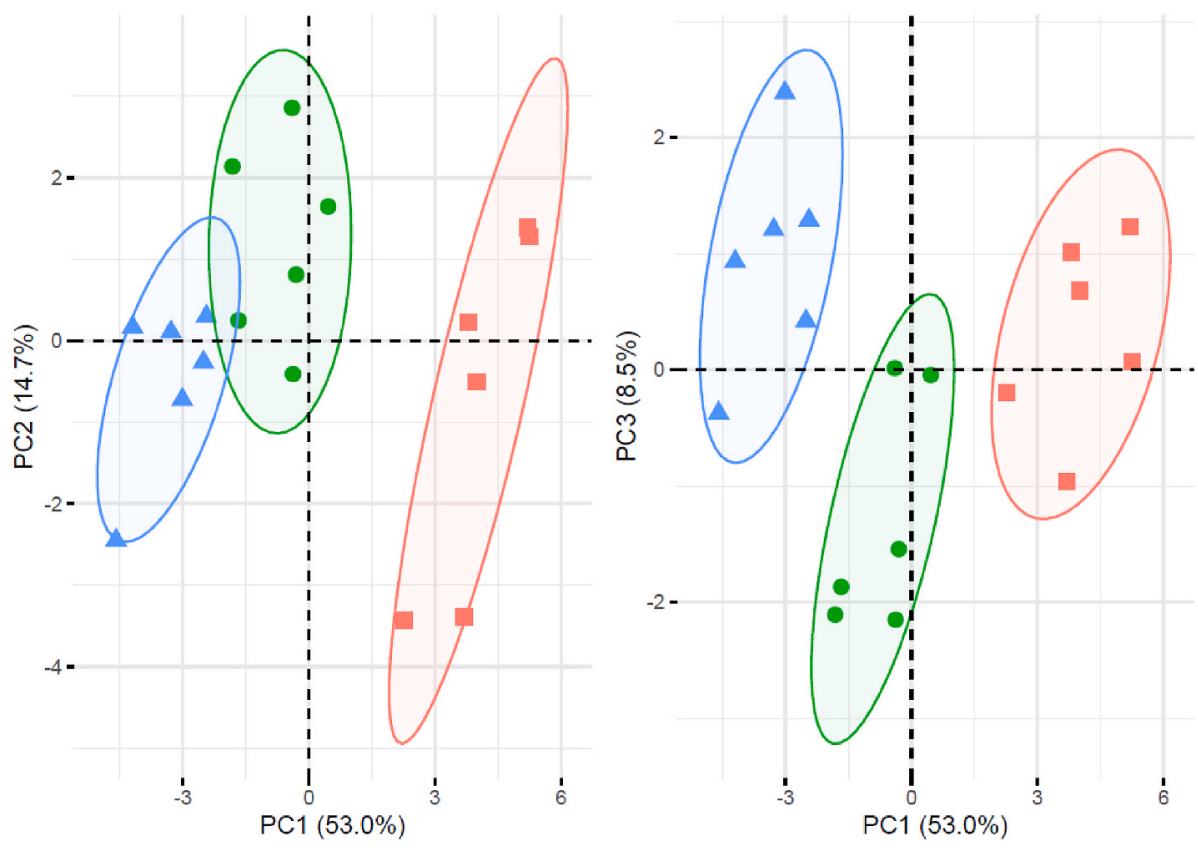

Fig. 3. $c v$. Cobrançosa monovarietal olive oils unsupervised classification (2D-PCA plots of the first 3 PCs) according to the different malaxation temperatures (ㅁ: $22^{\circ} \mathrm{C}$; $\bullet: 28{ }^{\circ} \mathrm{C}$; and, $\Delta: 34^{\circ} \mathrm{C}$ ) based on the intensities of 8 olfactory sensations (green, apple, tomato, dry fruits, cabbage, fresh herbs, tomato leaves and harmony) and 11 gustatory attributes (green, sweet, bitter, pungent, apple, tomato, dry fruits, cabbage, fresh herbs, tomato leaves and harmony), perceived by trained panellists. (For interpretation of the references to colour in this figure legend, the reader is referred to the Web version of this article.) 
sensations: apple, dry fruits and fresh herbs), which were the sensory attributes with the most discriminant power and thus the attributes mostly affected by the MT. The sensory-LDA-SA model had two linear discriminant functions, explaining the total data variability, and enabling the correct classifications of all samples for both original grouped data (Fig. 4A) and LOO-CV variant.

The E-tongue-LDA-SA model also had 2 discriminant functions (total data variability explained), was based on 8 selected non-redundant sensors (1st array: S1:3, S1:7, S1:15, S1:16; 2nd array: S2:1, S2:4, S2:18, S2:19) and also allowed the correct classification of all samples for both original grouped data (Fig. 4B) and LOO-CV.

The similar predictive classification performances achieved with both models demonstrated the possibility of using the E-tongue as a complementary/alternative tool (compared to the sensory analysis) for monitoring the changes on the global physicochemical and sensory quality of $c v$. Cobrançosa oils and so, allowing confirming the used MT through its effect on the oils' attributes. Nevertheless, it should be remarked that, contrary to the sensory analysis, for which both olfactory and gustatory attributes were evaluated by the trained panellists, the Etongue data can only mimic the gustatory sensations. Even so, the satisfactory performance achieved showed that the E-tongue could be used as a classification tool with similar accuracy as that obtained from the olfactory-gustatory attributes perceived by the trained panellists.

It should be noticed that, although both approaches allowed satisfactory discrimination of the oils according to the MT, the distribution of the groups within the 2D-LDA space is not similar (Fig. 4). A possible explanation would be the use of olfactory data from the sensory analysis, which cannot be assessed by the E-tongue. On the other hand, the lipid polymeric membranes comprised in the E-tongue, although capable of detecting different taste sensations, as recently reviewed by Wu, Tahara, et al. (2020), have global but low selectivity with cross-sensitivity, possessing the capability of responding to different analytes in solution and/or to produce a stable integrated response when multicomponent solutions are being analyzed (Vlasov, Legin, Rudnitskaya, Di Natale, \& D'Amico, 2005). So, probably, the E-tongue may detect other gustatory attributes that were not perceived or assessed by the trained panellists (attributes with higher human detection thresholds or with neutral gustatory sensations), which could partially explain the different observed 2D-LDA space group distributions.

The satisfactory discrimination power of the E-tongue could be tentatively attributed to the capability of this type of based-sensor taste device to qualitatively and/or quantitatively assess the physicochemical and sensory characteristics of olive oils, namely to discriminate oils with different TPC and sensory profiles/intensities (Borges et al., 2018; Rodrigues et al., 2019; Veloso et al., 2016). The capability of the E-tongue to indirectly identify the oils with the best overall physicochemical and sensory quality (i.e., those extracted at $22^{\circ} \mathrm{C}$ ) is utmost practical relevance mainly since it can be implemented at the hard operating conditions of an industrial olive mill plant, minimizing the main drawbacks of the sensory panels.

\section{Conclusions}

The literature data shows that the effect of the malaxation temperature on the physicochemical and sensory characteristics of olive oils produced from different olive cultivars, either in pilot or industrial plants, is not consensual, being contradictory increasing/decreasing trends reported. For the $c v$. Cobrançosa oils studied, which were extracted in an industrial plant, it was found, for the first time, that a lower malaxation temperature $\left(22^{\circ} \mathrm{C}\right)$ would allow obtaining olive oils with enhanced physicochemical quality (lower FA, PV and $K_{232}$ values and greater TPC) and sensory quality (more intense olfactory-gustatory attributes, namely bitter and pungent), without any expected significant yield loss as reported in the literature. Also, it was shown that decreasing the malaxation temperature allowed enriching the phenolic content of the oils and thus, the beneficial health effects related to their intake. On the other hand, it was also verified that a potentiometric electronic tongue could be used as a fast, green, user-friendly and accurate tool for discriminating the oils according to the malaxation temperature used $\left(22,28\right.$ or $\left.34^{\circ} \mathrm{C}\right)$ with a similar predictive performance of that achieved using the sensory data from the evaluation performed by trained panellists. In conclusion, the results demonstrated that the potentiometric taste-sensor device could be effectively used to minimize the limitations related with the scarcity of sensory panels, the low number of samples that can be evaluated per day and even the intrinsic subjectivity of the human analysis. In fact, the results allow foreseeing a future application of electronic tongues for monitoring the malaxation process during the olive oil extraction, guaranteeing to achieve an enhanced physicochemical and sensory quality and so to fulfil the preferences of specific consumers.

\section{CRediT authorship contribution statement}

Ítala M.G. Marx: Funding acquisition, Data curation, Formal
(A) Sensory-LDA-SA model

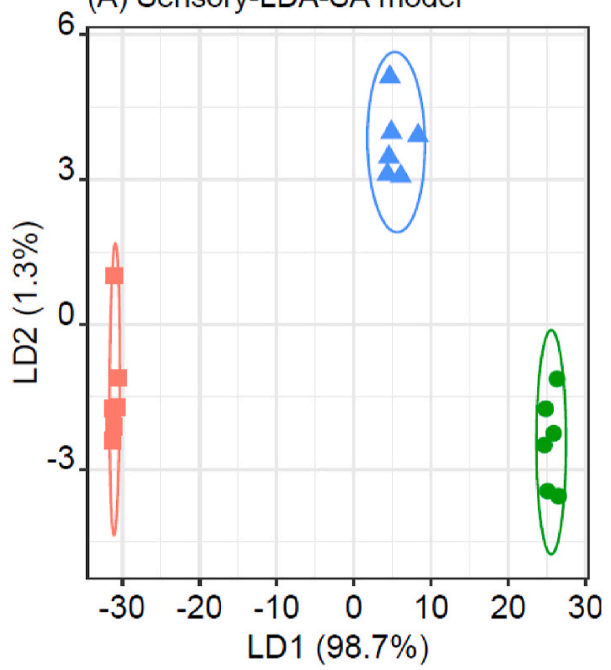

(B) E-tongue-LDA-SA model

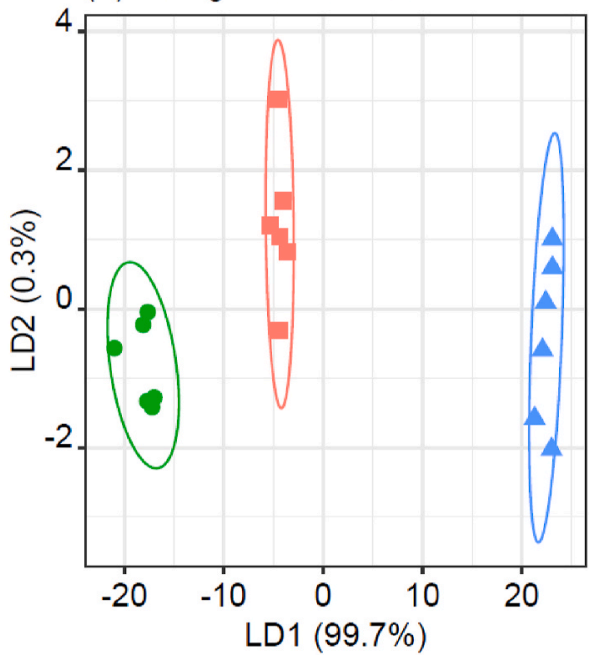

Fig. 4. LDA-SA model performance regarding the supervising classification of $\mathrm{cv}$. Cobrançosa monovarietal olive oils extracted at different malaxation temperature ( $\square: 22{ }^{\circ} \mathrm{C}$; $\bullet: 28{ }^{\circ} \mathrm{C}$; and, $\left.\Delta: 34^{\circ} \mathrm{C}\right)$ based on: (A) Intensities of 8 sensory sensations (olfactory: apple, cabbage, dry fruits, fresh herbs and tomato leaves; gustatory: apple, dry fruits, and fresh herbs) selected using the SA algorithm from 21 olfactory and gustatory attributes perceived by 8 trained panellists; and, (B) E-tongue potentiometric signals recorded by 8 sensors (1st sensor array: S1:3, S1:7, S1:15, S1:16; 2nd sensor array: S2:1, S2:4, S2:18, S2:19) selected using the SA algorithm from a set of 40 sensors. The ellipses represent the boundary lines based on the posterior probabilities computed using the Bayes' theorem for each class. 
analysis, Writing - original draft, Writing - review \& editng, Acquisition of data, Analysis and/or interpretation of data, Drafting the manuscript, Revising the manuscript critically for important intellectual content, Approval of the version of the manuscript to be submitted. Nuno Rodrigues: Funding acquisition, Data curation, Formal analysis, Writing - review \& editng, Acquisition of data, Analysis and/or interpretation of data, Revising the manuscript critically for important intellectual content, Approval of the version of the manuscript to be submitted. Ana C.A. Veloso: Funding acquisition, Data curation, Formal analysis, Writing - original draft, Writing - review \& editng, Acquisition of data, Analysis and/or interpretation of data, Drafting the manuscript, Revising the manuscript critically for important intellectual content, Approval of the version of the manuscript to be submitted. Susana Casal: Conceptualization, Formal analysis, Data curation, Writing - original draft, Writing - review \& editng, Conception and design the experiment, Analysis and/or interpretation of data, Drafting the manuscript, Revising the manuscript critically for important intellectual content, Approval of the version of the manuscript to be submitted. José A. Pereira: Conceptualization, Formal analysis, Data curation, Writing - original draft, Writing - review \& editng, Conception and design the experiment, Analysis and/or interpretation of data, Drafting the manuscript, Revising the manuscript critically for important intellectual content, Approval of the version of the manuscript to be submitted. António M. Peres: Conceptualization, Formal analysis, Data curation, Writing - original draft, Writing - review \& editng, Conception and design the experiment, Analysis and/or interpretation of data, Drafting the manuscript, Revising the manuscript critically for important intellectual content, Approval of the version of the manuscript to be submitted.

\section{Declaration of competing interest}

The authors declare that they have no known competing financial interests or personal relationships that could have appeared to influence the work reported in this paper.

\section{Acknowledgments}

The authors are grateful to the Foundation for Science and Technology (FCT, Portugal) for financial support by national funds FCT/ MCTES to CIMO (UIDB/00690/2020), to CEB (UIDB/04469/2020), to REQUIMTE-LAQV (UIDB/50006/2020) units and to BioTecNorte operation (NORTE-01-0145-FEDER-000004) funded by the European Regional Development Fund under the scope of Norte 2020 - Programa Operacional Regional do Norte. Ítala M.G. Marx also acknowledges the PhD research grant (SFRH/BD/137283/2018) provided by FCT. Nuno Rodrigues thanks to National funding by FCT- Foundation for Science and Technology, P.I., through the institutional scientific employment program-contract.

\section{Appendix A. Supplementary data}

Supplementary data to this article can be found online at https://doi. org/10.1016/j.lwt.2020.110426.

\section{References}

Angerosa, F., Mostallino, R., Basti, C., \& Raffaella, V. (2001). Influence of malaxation temperature and time on the quality of virgin olive oils. Food Chemistry, 72(1), 19-28. https://doi.org/10.1016/S0308-8146(00)00194-1

Apetrei, C., Ghasemi-Varnamkhasti, M., \& Apetrei, I. M. (2016). Olive oil and combined electronic nose and tongue. In V. Preedy, \& M. L. Rodríguez-Méndez (Eds.), Electronic Noses and Tongues in food science (pp. 277-289). London: Academic Press. https:// doi.org/10.1016/B978-0-12-800243-8.00027-5.

Arca, V. C., Peres, A. M., Machado, A. A., Bona, E., \& Dias, L. G. (2019). Sugars' quantifications using a potentiometric electronic tongue with cross-selective sensors: Influence of an ionic background. Chemosensors, 7(3), Article 43. https://doi.org/ $10.3390 /$ chemosensors7030043
Bertsimas, D., \& Tsitsiklis, J. (1993). Simulated annealing. Statistical Science, 8, 10-15.

Borges, T. H., Peres, A. M., Dias, L. G., Seiquer, I., \& Pereira, J. A. (2018). Application of a potentiometric electronic tongue for assessing phenolic and volatile profiles of Arbequina extra virgin olive oils. LWT-Food Science and Technology, 93, 150-157. https://doi.org/10.1016/j.lwt.2018.03.025

Boselli, E., Di Lecce, G., Strabbioli, R., Pieralisi, G., \& Frega, N. G. (2009). Are virgin olive oils obtained below $27^{\circ} \mathrm{C}$ better than those produced at higher temperatures? LWTFood Science and Technology, 42(3), 748-757. https://doi.org/10.1016/j. lwt.2008.09.018

Cadima, J., Cerdeira, J. O., \& Minhoto, M. (2004). Computational aspects of algorithms for variable selection in the context of principal components. Computational Statistics \& Data Analysis, 47(2), 225-236. https://doi.org/10.1016/j.csda.2003.11.001

Capannesi, C., Palchetti, I., Mascini, M., \& Parenti, A. (2000). Electrochemical sensor and biosensor for polyphenols detection in olive oils. Food Chemistry, 71(4), 553-562. https://doi.org/10.1016/S0308-8146(00)00211-9

Clodoveo, M. L. (2012). Malaxation: Influence on virgin olive oil quality. Past, present and future - an overview. Trends in Food Science \& Technology, 25(1), 13-23. https:// doi.org/10.1016/j.tifs.2011.11.004

Commission Delegated Regulation (EU) No 2015/1830 of 8th July 2015. (2015). Amending Regulation (EEC) $N^{\circ} 2568 / 91$ on the characteristics of olive oil and oliveresidue oil and on therelevant methods of analysis. Official Journal of the European Union, L266, 9-13.

Napolitano, A., De Lucia, M., Panzella, L., \& D'Ischia, M. (2010). The chemistry of tyrosol and hydroxytyrosol: Implications for oxidative stress. Olives and olive oil in health and disease prevention, 1225-1232. https://doi.org/10.1016/B978-0-12-3744203.00134-0. Academic Press.

Commission Regulation (EEC) No 2568/91 of 11 July 1991. (1991). On the characteristics of olive oil and olive-residue oil and on the relevant methods of analysis. Official Journal of the European Union, L248, 1-83.

Commission Regulation (EC) $N^{\circ} 432 / 2012$. (2012). Establishing a list of permitted health claims made on foods, other than those referring to the reduction of disease risk and to children's development and health. Official Journal of the European Union, L136, $1-40$.

Covas, M., de la Torre, K., Farré-Albaladejo, M., Kaikkonen, J., Fitó, M., LópezSabater, C., et al. (2006). Postprandial LDL phenolic content and LDL oxidation are modulated by olive oil phenolic compounds in humans. Free Radical Biology and Medicine, 40(4), 608-616. https://doi.org/10.1016/j.freeradbiomed.2005.09.027

Di Giovacchino, L., Sestili, S., \& Di Vincenzo, D. (2002). Influence of olive processing on virgin olive oil quality. European Journal of Lipid Science and Technology, 104, 587-601. https://doi.org/10.1002/1438-9312(200210)104:9/10<587::AIDEJLT587>3.0.CO;2-M

Dias, L. A., Peres, A. M., Veloso, A. C. A., Reis, F. S., Vilas-Boas, M., \& Machado, A. A. S. C. (2009). An electronic tongue taste evaluation: Identification of goat milk adulteration with bovine milk. Sensors and Actuators B: Chemical, 136(1), 209-217. https://doi.org/10.1016/j.snb.2008.09.025

Gómez-Rico, A., Inarejos-García, A. M., Salvador, M. D., \& Fregapane, G. (2009). Effect of malaxation conditions on phenol and volatile profiles in olive paste and the corresponding virgin olive oils (Olea europaea L. Cv. cornicabra). Journal of Agricultural and Food Chemistry, 57(9), 3587-3595. https://doi.org/10.1021/ jf803505w

Guerrini, L., Masella, P., Angeloni, G., Zanoni, B., Breschi, C., Calamai, L., et al. (2019). The effect of an increase in paste temperature between malaxation and centrifugation on olive oil quality and Yield : Preliminary results. Italian Journal of Food Science, 31, 451-458. https://doi.org/10.14674/IJFS-1393

Harzalli, U., Rodrigues, N., Veloso, A. C. A., Dias, L. G., Pereira, J. A., Oueslati, S., et al. (2018). A taste sensor device for unmasking admixing of rancid or winey-vinegary olive oil to extra virgin olive oil. Computers and Electronics in Agriculture, 144, 222-231. https://doi.org/10.1016/j.compag.2017.12.016

IOC, International Olive Council. (2005). Sensory analysis of olive oil - method for the organoleptic assessment of virgin olive oil applying to use a designation of origin, COI/ T.20/Doc. No, 22 November 2005.

Inajeros-García, A., Gómez-Rico, A., Salvador, M. D., \& Fregapane, G. (2009). Influence of malaxation conditions on virgin olive oil yield, overall quality and composition. European Food Research and Technology, 228, 671-677. https://doi.org/10.1007/ s00217-008-0977-9

Jeong, H.-M., Kwon, H.-C., Xu, B., Jung, D., Han, M., Kwon, D.-H., et al. (2020). Taste sensor based on the floating gate structure of a lateral double-diffused metal-oxide semiconductor. Sensors and Actuators B: Chemical, 308, Article 127661. https://doi. org/10.1016/j.snb.2020.127661

Jiménez, B., Sánchez-Ortiz, A., \& Rivas, A. (2014). Influence of the malaxation time and olive ripening stage on oil quality and phenolic compounds of virgin olive oils. Food Science and Technology, 49(11), 2521-2527. https://doi.org/10.1111/ijfs.12592

Kalua, C. M., Allen, M. S., Bedgood, D. R., Bishop, A. G., Prenzler, P. D., \& Robards, K. (2007). Olive oil volatile compounds, flavour development and quality: A critical review. Food Chemistry, 100(1), 273-286. https://doi.org/10.1016/j. foodchem.2005.09.059

Lanza, B., \& Amoruso, F. (2020). Panel performance, discrimination power of descriptors, and sensory characterization of table olive samples. Journal of Sensory Studies, 35(1), 1-15. https://doi.org/10.1111/joss.12542

Lukić, I., Žanetić, M., Jukić Špika, M., Lukić, M., Koprivnjak, O., \& Brkić Bubola, K. (2017). Complex interactive effects of ripening degree, malaxation duration and temperature on Oblica cv. virgin olive oil phenols, volatiles and sensory quality. Food Chemistry, 232, 610-620. https://doi.org/10.1016/j.foodchem.2017.04.047

Marx, Í. M. G., Rodrigues, N., Dias, L. G., Veloso, A. C. A., Pereira, J. A., Drunkler, D. A., et al. (2017a). Quantification of table olives' acid, bitter and salty tastes using 
potentiometric electronic tongue fingerprints. LWT- Food Science and Technology, 79, 394-401. https://doi.org/10.1016/j.lwt.2017.01.060

Marković, A. K., Torić, J., Barbarić, M., \& Brala, C. J. (2019). Hydroxytyrosol, tyrosol and derivatives and their potential effects on human health. Molecules, 24(10), Article 2001. https://doi.org/10.3390/molecules24102001

Marx, Í., Rodrigues, N., Dias, L. G., Veloso, A. C. A., Pereira, J. A., Drunkler, D. A., et al. (2017b). Sensory classification of table olives using an electronic tongue: Analysis of aqueous pastes and brines. Talanta, 162, 98-106. https://doi.org/10.1016/j. talanta.2016.10.028

Marx, Í. M. G., Veloso, A. C. A., Dias, L. G., Casal, S., Pereira, J. A., \& Peres, A. M. (2018). Electrochemical sensor-based devices for assessing bioactive compounds in olive oils: A brief review. Electronics, 7, 387. https://doi.org/10.3390/electronics7120387

Miho, H., Moral, J., López-González, M. A., Díez, C. M., \& Priego-Capote, F. (2020). The phenolic profile of virgin olive oil is influenced by malaxation conditions and determines the oxidative stability. Food Chemistry, 314, 126183. https://doi.org/ 10.1016/j.foodchem.2020.126183

Oohira, K., \& Toko, K. (1996). Theory of electric characteristics of the lipid/PVC/DOPP membrane and PVC/DOPP membrane in response to taste stimuli. Biophysical Chemistry, 61, 29-35. https://doi.org/10.1016/0301-4622(96)00026-9

Oohira, K., Toko, K., Akiyama, H., Yoshihara, H., \& Yamafuji, K. (1995). Electric characteristics of hybrid polymer membranes composed of two lipid species. Journal of the Physical Society of Japan, 64, 3554-3561. https://doi.org/10.1143/ JPSJ.64.3554

Parenti, A., Spugnoli, P., Masella, P., \& Calamai, L. (2008). The effect of malaxation temperature on the virgin olive oil phenolic profile under laboratory-scale conditions. European Journal of Lipid Science and Technology, 110(8), 735-741. https://doi.org/10.1002/ejlt.200700307

Pereira, C., Costa Freitas, A. M., Cabrita, M. J., \& Garcia, R. (2020). Assessing tyrosol and hydroxytyrosol in Portuguese monovarietal olive oils: Revealing the nutraceutical potential by a combined spectroscopic and chromatographic techniques - based approach. LWT- Food Science and Technology, 118, Article 108797. https://doi.org/ 10.1016/j.lwt.2019.108797

Peres, F., Martins, L. L., Mourato, M., Vitorino, C., \& Ferreira-Dias, S. (2016). Bioactive compounds of Portuguese virgin olive oils discriminate cultivar and ripening stage. JAOCS, Journal of the American Oil Chemists' Society, 93(8), 1137-1147. https://doi. org/10.1007/s11746-016-2848-Z

Peyrot Des Gachons, C., Uchida, K., Bryant, B., Shima, A., Sperry, J. B., DankulichNagrudny, L., et al. (2011). Unusual pungency from extra-virgin olive oil is attributable to restricted spatial expression of the receptor of oleocanthal. Journal of Neuroscience, 31(3), 999-1009. https://doi.org/10.1523/JNEUROSCI.1374-10.2011

Ranalli, A., Contento, S., Schiavone, C., \& Simone, N. (2001). Malaxing temperature affects volatile and phenol composition as well as other analytical features of virgin olive oil. European Journal of Lipid Science and Technology, 103(4), 228-238. https:// doi.org/10.1002/1438-9312(200104)103:4<228::AID-EJLT228>3.0.CO;2-7

Ranalli, A., Malfatti, A., Lucera, L., Contento, S., \& Sotiriou, E. (2005). Effects of processing techniques on the natural colourings and the other functional constituents in virgin olive oil. Food Research International, 38(8-9), 873-878. https://doi.org/10.1016/j.foodres.2005.02.011

Rodrigues, N., Casal, S., Peres, A. M., Baptista, P., \& Pereira, J. A. (2020). Seeking for sensory differentiated olive oils? The urge to preserve old autochthonous olive cultivars. Food Research International, 128, 108759. https://doi.org/10.1016/j. foodres.2019.108759

Rodrigues, N., Dias, L. G., Veloso, A. C. A., Pereira, J. A., \& Peres, A. (2017). Evaluation of extra-virgin olive oils shelf life using an electronic tongue-chemometric approach. European Food Research and Technology, 243, 597-607. https://doi.org/ 10.1007/s00217-016-2773-2

Rodrigues, N., Marx, Í. M. G., Casal, S., Dias, L. G., Veloso, A. C. A., Pereira, J. A., et al. (2019). Application of an electronic tongue as a single-run tool for olive oils' physicochemical and sensory simultaneous assessment. Talanta, 197, 363-373. https://doi.org/10.1016/j.talanta.2019.01.055
Servili, M., \& Montedoro, G. (2002). Contribution of phenolic compouns to virgin olive oil quality. European Journal of Lipid Science and Technology, 104, 602-613. https:// doi.org/10.1002/1438-9312(200210)104:9/10<602::AID-EJLT602>3.0.CO;2-X

Servili, M., Selvaggini, R., Taticchi, A., Esposto, S., \& Montedoro, G. F. (2003). Volatile compounds and phenolic composition of virgin olive oil: Optimization of temperature and time of exposure of olive pastes to air contact during the mechanical extraction process. Journal of Agricultural and Food Chemistry, 51(27), 7980-7988. https://doi.org/10.1021/jf034804k

Servili, M., Taticchi, A., Esposto, S., Urbani, S., Selvaggini, R., \& Montedoro, G. (2008). Influence of the decrease in oxygen during malaxation of olive paste on the composition of volatiles and phenolic compounds in virgin olive oil. Journal of Agricultural and Food Chemistry, 56(21), 10048-10055. https://doi.org/10.1021/ jf800694h

Sharma, G., Kumar, S., Kumar, A., Sharma, A., Kumar, R., Kaur, R., et al. (2015). Development of lipid membrane based taste sensors for electronic tongue. Procedia Computer Science, 70, 146-152. https://doi.org/10.1016/j.procs.2015.10.062

Slim, S., Rodrigues, N., Dias, L. G., Veloso, A. C. A., Pereira, J. A., Oueslati, S., et al. (2017). Application of an electronic tongue for Tunisian olive oils' classification according to olive cultivar or physicochemical parameters. European Food Research and Technology, 243, 1459-1470. https://doi.org/10.1007/s00217-017-2856-8

Stefanoudaki, E., Koutsaftakis, A., \& Harwood, J. L. (2011). Influence of malaxation conditions on characteristic qualities of olive oil. Food Chemistry, 127(4), 1481-1486. https://doi.org/10.1016/j.foodchem.2011.01.120

Taticchi, A., Esposto, S., Veneziani, G., Urbani, S., Selvaggini, R., \& Servili, M. (2013) The influence of the malaxation temperature on the activity of polyphenoloxidase and peroxidase and on the phenolic composition of virgin olive oil. Food Chemistry, 136(2), 975-983. https://doi.org/10.1016/j.foodchem.2012.08.071

Toko, K., Hara, D., Tahara, Y., Yasuura, M., \& Ikezaki, H. (2014). Relationship between the amount of bitter substances adsorbed onto lipid/polymer membrane and the electric response of taste sensors. Sensors, 14(9), 16274-16286. https://doi.org/ 10.3390/s140916274

Trapani, S., Breschi, C., Cecchi, L., Guerrini, L., Mulinacci, N., Parenti, A., et al. (2017). Indirect indices of oxidative damage to phenolic compounds for the implementation of olive paste malaxation optimization charts. Journal of Food Engineering, 207, 24-34. https://doi.org/10.1016/j.jfoodeng.2017.03.012

Veloso, A. C. A., Dias, L. G., Rodrigues, N., Pereira, J. A., \& Peres, A. M. (2016). Sensory intensity assessment of olive oils using an electronic tongue. Talanta, 146, 585-593. https://doi.org/10.1016/j.talanta.2015.08.071

Veloso, A. C. A., Silva, L. M., Rodrigues, N., Rebello, L. P. G., Dias, L. G., Pereira, J. A., et al. (2018). Perception of olive oils sensory defects using a potentiometric taste device. Talanta, 176, 610-618. https://doi.org/10.1016/j.talanta.2017.08.066

Venables, W. N., \& Ripley, R. B. (2002). In Modern applied statistics with S (statistics and computing) (4th ed.). New York: Springer. https://doi.org/10.1007/978-0-38721706-2.

Veneziani, G., Esposto, S., Taticchi, A., Urbani, S., Selvaggini, R., Di Maio, I., et al. (2017). Cooling treatment of olive paste during the oil processing: Impact on the yield and extra virgin olive oil quality. Food Chemistry, 221, 107-113. https://doi. org/10.1016/j.foodchem.2016.10.067

Vlasov, Y., Legin, A., Rudnitskaya, A., Di Natale, C., \& D'Amico, C. (2005). Nonspecific sensor arrays ("electronic tongue") for chemical analysis of liquids: (IUPAC technical report). Pure and Applied Chemistry, 77, 1965-1983. https://doi.org/10.1351/ pac200577111965

Wu, X., Miyake, K., Tahara, Y., Fujimoto, H., Iwai, K., Narita, Y., et al. (2020). Quantification of bitterness of coffee in the presence of high-potency sweeteners using taste sensors. Sensors and Actuators B: Chemical, 309, Article 127784. https:// doi.org/10.1016/j.snb.2020.127784

Wu, X., Tahara, Y., Yatabe, R., \& Toko, K. (2020). Taste sensor: Electronic tongue with lipid membranes. Analytical Sciences, 36, 147-159. https://doi.org/10.2116/ analsci.19R008

Yasuura, M., Shen, Q., Tahara, Y., Yatabe, R., \& Toko, K. (2015). Development and investigation of a sweetness sensor for sugars - effect of lipids -. Sensors and Materials, 27(5), 351-358. https://doi.org/10.18494/SAM.2015.1073 